\title{
Gebelerde Uyku Kalitesi ve Yaşam Kalitesi
}

\section{Sleep Quality and Quality of Life in Pregnants}

\author{
Yasemin ÖZHÜNER ${ }^{\mathrm{a}}$ Neşe ÇELIKK
}

ÖZ Amaç: Bu çalışmada, gebelerin uyku kalitesi ve yaşam kalitesinin değerlendirilmesi ve aralarındaki ilişkinin belirlenmesi amaçlanmıştır. Gereç ve Yöntemler: Kesitsel tipte tasarlanan bu çalışma Eskişehir ilinde üç farklı Aile Sağlığı Merkezi’nde 386 gebenin katılımı ile yapıldı. Araştırmada, veri toplama aracı olarak "Pittsburgh Uyku Kalitesi İndeksi" ve "SF-36 Yaşam Kalitesi Ölçeği" ve ilişkili faktörleri değerlendirebilmek için bir anket formu kullanıldı.Bulgular: Bu çalışmada gebelerin Pittsburgh Uyku Kalitesi İndeksi puan ortalaması 10.04 \pm 2.98 olup \%57.8'inin uyku kalitesi kötüdür. SF-36 Yaşam kalitesi ölçeği alt boyutlarından alınan puan ortalamaları $26.29 \pm 33.73$ ile 55.66 \pm 21.65 arasında değişmekteydi. Gebelerin Pittsburgh Uyku Kalitesi İndeksi global skoru ile yaşam kalitesi alt boyutlarının puan ortalamaları arasında negatif yönde anlamlı bir korelasyon bulundu. Gebelerin Pittsburgh Uyku Kalitesi İndeksi’nden aldıkları puanlar arttıkça yaşam kalitesi alt boyutlarından alınan puanlar azalmaktaydı $(\mathrm{p}<0.05)$.Sonuç: Bu çalışmaya göre gebelerin yarısından fazlasının uyku kalitesi kötüdür. Gebelerin yaşam kalitesi orta ve orta düzeyin altındadır ve uyku kalitesi kötüleştikçe yaşam kalitesi düşmekte ve olumsuz etkilenmektedir.

Anahtar Kelimeler: Gebelik; uyku kalitesi; yaşam kalitesi.

ABSTRACT Aim: The aim of this study was to evaluate the sleep quality and quality of life and to determine the relation between them. Method: This descriptive study was conducted of the study 386 pregnant women who applied to the three different family health center in Eskişehir. In this study, Pittsburg Sleep Quality Index and SF36 Quality of Life Survey and a questionnaire that was used as data collection tools to assess the factors associated. Results: In the study, it was seen that $57.8 \%$ had poor sleep quality and the mean of Pittsburg Sleep Quality Index score was found as $10.04 \pm 2.98$. The mean scores of the SF-36 Quality of Life Survey subscales ranged from 26.29 \pm 33.73 to $55.66 \pm 21.65$. There was a negative significant correlation between the Pittsburg Sleep Quality Index global score and the mean score of the quality of life subscales. As the scores of pregnant women from Pittsburg Sleep Quality Index increased, scores from the quality of life subscales decreased $(p<0.05)$. Conclusion: The findings of the study suggests that of more than half of the pregnancies have poor sleep quality. The quality of life of pregnant women is moderate and low. The poor sleep quality of pregnant women affects the quality of life negatively.

Keywords: Quality of life, pregnancy; sleep quality

\section{Giriş}

Uyku, bütün insanlar için önemli fizyolojik bir gereksinimdir. Kaliteli uyku zihinsel ve fiziksel sağlığı ve hayat kalitesini korumaya yardım eder (1). Uyku; bilincin geçici kaybolmas1, organik faaliyetlerin özellikle sinir duyusunun ve istemli

kas hareketlerinin azalmasıyla ortaya çıkan normal, geçici, periyodik ve psikofizyolojik bir durum olarak tanımlanmaktadır (2). Gebelikte kadınlar hormonal ve fiziksel değişikliklerin oluşması sonucunda uyku sorunları yaşayabilmektedir. İlk

Geliş Tarihi/Received:19-06-2018 / Kabul Tarihi/Accepted:15-10-2018

aBilim Uzmanı, Vadişehir Aile Sağlığı Merkezi, Vadişehir Mah. Özlem Cd. No:3 Eskişehir, Türkiye, e-posta: canannury @ hotmail.com, ORCID: 0000-0002-6040-1143

bDr. Öğr. Üyesi, Eskişehir Osmangazi Üniversitesi Sağlık Bilimleri Fakültesi Ebelik Bölümü, Eskişehir, Türkiye, e posta: ncelik@ogu.edu.tr, ORCID:0000-0002-2071-5615

*Yüksek Lisans tezinden türetilmiş olup daha önce başka bir dergi, kongre veya sempozyumda sunulmamıştır.

Sorumlu Yazar/Correspondence: Dr. Öğr. Üyesi Neşe Çelik, Eskişehir Osmangazi Üniversitesi Sağlık Bilimleri Fakültesi Ebelik Bölümü, e-posta: ncelik@ogu.edu.tr,

Atıf: Özhüner Y, Çelik N. Gebelerde uyku kalitesi ve yaşam kalitesi. Sağlık Bilimleri ve Meslekleri Dergisi 2019;6(1):25-33

Citation: Özhüner Y, Çelik N. Sleep qualıty and qualıty of life in pregnants. Journal of Health Science and Profession 2019;6(1):25-33 
trimesterde başlayıp özellikle üçüncü trimesterde uyku siklıkla bozulmaktadır $(3,4)$. Gebelerde uyku bozukluklarının insidansı tam olarak bilinmemektedir. Fakat birinci trimesterden başlayıp üçüncü trimesterde en yüksek değerde olduğu bildirilmektedir (5). Bir çalışmada uyku bozukluğu s1klığ1 gebeliğin üçüncü trimesterinde $\% 97$ olarak bulunmuştur (6). Yapılan çalışmalarda gebelikte uyku kalitesinin bulantı, sırt ağrısı, hormonal değişimler, fetüsün büyümesi, sık idrara çıkma, bacak krampları, huzursuz bacak sendromu, horlama gibi semptomlardan etkilendiğini bildirmektedir $(4,5,6)$.

Yaşam kalitesi geniş bir kavram olup bireyin iyilik halini, yaşamın farklı alanlarında öznel bir doyumu ifade etmektedir. Dünya Sağlık Örgütü'ne göre (DSÖ) yaşam kalitesi; bireylerin yaşamındaki kültür ve değerler içinde oluşan amaçları, beklentileri, ilgi alanları ve hayat standartlarına bağlı olarak kendilerini nasıl algıladıkları olarak tanımlanmaktadır (7). Yaşam kalitesi aile, iş yaşamı, sosyoekonomik koşullar ile kişinin hedefleri, beklentileri, umutları, düşleri ile gerçekler arasındaki farklılığı açıklayan bir kavram olup kişinin günlük yaşamından aldığı doyum ve iyilik algısını içerir (8).

Gebelikte oluşan hormonal, fizyolojik ve ruhsal değişimler uyku kalitesini olduğu gibi yaşam kalitesini de etkilemektedir (9). Yapılan bir çalışmada gebelikte meydana gelen değişimlerin yaşam kalitesini azalttığı bildirilmiştir (10). Gebelerde oluşan fiziksel semptomlar, yorgunluk, duygusal değişimler ve yaşanan sinırlılıkların yaşam kalitesinin birçok alanında azalmaya neden olduğu da başka bir çalışmada belirtilmiştir (11).

Gebelerin fizyolojik, psikolojik ve sosyal açıdan oluşan değişikliklere uyum sağlayabilmelerinde sağlık profesyonellerinin büyük katkıları bulunmaktadır. Sağlık profesyonelleri, düzenli kontrol ve izlemlerle gebelerin gereksinimlerini veya problemlerinin belirleyerek gebeliklerini daha kolay geçirmelerine yardımcı olarak ve yaşam kalitelerini yükseltmeye çalışmaktadırlar. Gebelerin uyku kalitesini ve yaşam kalitesini değerlendirmek anne adaylarının sağliklı bir gebelik geçirebilmesi için erken önlem alma ve çözüm bulma açısından önemlidir. Bu nedenle bu çalışmada gebelerin uyku kalitesi ve yaşam kalitesinin değerlendirilmesi ve aralarındaki ilişkinin belirlenmesi amaçlanmıştır.

\section{Gereç ve Yöntem}

$\mathrm{Bu}$ çalışma, 28 Nisan 2016-30Ağustos 2016 tarihleri arasında Türkiye'de Eskişehir İl Halk Sağlığ1 Müdürlügüne bağlı Emek, Vadişehir ve Eskişehir Osmangazi Üniversitesi Aile Sağllğ Merkez'lerinde izlemleri yapılan 386 gebe ile gerçekleştirilen kesitsel tipte bir araştırmadır. Çalışmanın evrenini Eskişehir İli Halk Sağlığ Müdürlüğü'ne bağlı tüm Aile Sağlığ1 Merkezleri (ASM) ne başvuran gebe sayis1 oluşturdu. Çalışmada gerekli başvurular yapılmasına rağmen evren sayısına ulaşılamadı. Evrenin belli olmadığ 1 durumlarda kullanılan hesaplama formülü ile örneklem sayısı belirlenmiştir. Örnekleme alınan gebelerin sayısinın hesaplanmasi; formülde; t:1.96, p: 0.50; q: 0.50; d: 0.05 (\%95 güvenirlik) değerleri kullanılmıştır. Buna göre $\mathrm{n}=\mathrm{t}^{2} \mathrm{p} \mathrm{q} / \mathrm{d}^{2}$ formülü ile $(1.96)^{2} \times(0.50) \times(0.50) \div(0.05)^{2}=386$ kişi olarak örneklem sayısı belirlenmiştir.

\section{Veri Toplama Araçları}

$\mathrm{Bu}$ çalışmada veri toplama aracı olarak gebelerin sosyo-demografik bilgilerini, gebelik özelliklerini ve uyku ve yaşam kalitesi ile ilişkili olabilecek değişkenleri içeren sorulardan oluşan bir soru formu ile birlikte Pittsburgh Uyku Kalitesi İndeksi (PUKİ) ve SF-36 Yaşam Kalitesi Ölçeği kullanıldı. Araştırmanın bağımlı değişkeni uyku kalitesi; temel bağımsız değişkeni yaşam kalitesi, diğer bağımsız değişkenleri ise gebelerin sosyodemografik ve gebelikle ilgili özellikleri (yaş, eğitim durumu, mesleği, nerede yaşadığı, vücut kitle indeksi (VKI), gelir durumu, mesken içinde yaşayan birey sayıs1, sigara kullanımı, toplam gebelik sayıs1, gebeliği isteyip istemediği, gebelikte eşlik eden bir hastalığın varlığ 1 , gebelik öncesi uyku düzenidir.

Pittsburg Uyku Kalitesi İndeksi (PUKİ): Buysse ve arkadaşları (12). (1988) tarafından geliştirilen PUKI'nin geçerlik ve güvenirlik çalışmaları, 1996 y1lında Ağargün ve arkadaşları (13). tarafindan yapılarak ülkemize uyarlanmıştır $(12,13)$. PUKI uyku kalitesini; öznel uyku kalitesi, uyku latensi, uyku süresi, alışılmış uyku etkinliği, uyku bozukluğu, uyku ilacı kullanımı ve gündüz işlev bozukluğu olmak üzere yedi alt bileşende değerlendirmektedir. PUKİ'den alınan toplam puan beşin üzerinde olanlar uyku kalitesi "kötü”, beş ve altı olanlar "iyi" olarak değerlendirilmektedir. 
Yaşam Kalitesi Ölçeği (Short-Form Health Survey (SF-36): Ware ve Sherbourne ${ }^{14}$ (1992) tarafindan geliştirilen bu ölçeğin, Türkçe dil ve geçerlik, güvenirlik çalışması Pınar $^{15}$ (1995) tarafından yapılmıştır $(14,15)$. Ölçek 36 madde ve sekiz alt boyuttan oluşmaktadır. Ölçeğin alt boyutlarında fiziksel fonksiyon, sosyal fonksiyon, fiziksel fonksiyona bağlı rol kısitllikları, emosyonel sorunlara bağlı rol kısıtlılıkları, mental sağlık, enerji/vitalite, ağrı ve genel sağlığın algılanması bulunmaktadır. Ölçeğin değerlendirmesinde her bir alt boyuttan 0-100 puan arasinda puan elde edilmekte, 0 puan yaşam kalitesi boyutunun kötü olduğunu, 100 puan ise iyi olduğunu belirtmektedir.

\section{Veri Toplama Prosedürü}

Çalışmaya 18 yaş üstü, okur-yazar olan, görme ve işitme engeli olmayan gebeler dahil edilmiştir. Çalışmaya başlamadan önce katılımcılara çalışma hakkında sözlü bilgi verilip yazılı bilgilendirilmiş onamları alınmıştır. Gebeler anket formlarını kendileri doldurmuş olup veri toplama süresi yaklaşık 25-30 dk sürmüştür.

\section{İstatistiksel Analiz}

Elde edilen veriler, bilgisayar ortamında IBM SPSS (versiyon 20.0) istatistik paket programında değerlendirilmiştir. Veriler için normalite testi yapılmış olup normal dağılım göstermeyen veriler için nonparametrik testler kullanılmıştır. Tanımlayıcı veriler sayı, yüzde, ortalama ve standart sapma kullanılmıştır. Sayım verilerinin karşılaştırılmasında ki-kare, ölçüm verilerinin karşılaştırılmasında Mann Whitney U testi, ikiden fazla grubun karşılaştırılmasında Kruskal Wallis Testi kullanılmıştır. Ölçek puanları arasındaki ilişki Spearman korelasyon analizi ve lojistik regresyon analizi ile değerlendirilmiştir. İstatistiksel anlamlılık değeri olarak $\mathrm{p}<0.05$ kabul edilmiştir.

\section{Etik ve Yasal Durum}

Araştırmanın yapılabilmesi için Eskişehir Osmangazi Üniversitesi Girişimsel Olmayan Klinik Araştırmalar Etik Kurul Başkanlı̆̆ı'ndan etik kurul onay1 (18 Nisan 2016, Say1:80558721/G101) alınmıştır. Eskişehir Valiliği İl Sağlık Müdürlüğü'nden yasal yazılı izin ve katılımcılardan yazılı bilgilendirilmiş onam alınmıştır.

\section{Bulgular}

Bu çalışmada gebelerin \% 40.4 'ü 30 yaş ve üzerinde olup yaş ortalaması $28.80 \pm 6.12$ 'dir. Gebelerin genel olarak \%57.8'inin kötü, \%42.2'sinin iyi uyku kalitesine sahip olduğu saptanmıştır. Gebelerin sosyo-demografik özellikleri ile uyku kalitesi arasındaki ilişki incelendiğinde yaş1 30 ve üzerinde olan ve 5-8 kişilik bir ailede yaşayan gebelerin uyku kalitesinin kötü olduğu saptanmıştır (her biri için; p<0.05). Gebelik öncesi VKİ'ye göre; fazla kilolu olan gebelerin daha fazla oranda kötü uyku kalitelerinin olduğu belirlenmiştir $(\mathrm{p}<0.05) . \mathrm{Bu}$ çalışmada öğrenim düzeyi, çalışma durumu, yaşanılan yer, ekonomik durum ve sigara içme durumu gibi değişkenler ile uyku kalitesi arasında bir anlamlı düzeyde bir ilişki saptanmamıştır (p>0.05) (Tablo 1). Bu çalışmada üçüncü trimesterde olan gebelerin kötü uyku kalitesi sıklığ diğer trimesterlara göre anlamlı düzeyde daha fazla bulunmuştur $(\mathrm{p}<0.05)$ (Tablo 2). Yapılan lojistik regresyon analizine göre 3 . trimesterde olan gebelerin diğer trimesterde olan gebelere göre kötü uyku kalitesi riskinin 8.60 kat daha fazla olduğu tespit edilmiştir (\%95 güven aralığı: 3.70-19.99; $\mathrm{p}<0.000)$.

Toplam gebelik sayısı dört ve üzerinde olan, yaşayan çocuk sayısı iki ve üzerinde olan, gebeliği planlı olmayanların, gebelikte eşlik eden bir hastalığ 1 olanların ve gebelik öncesinde uyku düzenini düzensiz olarak ifade eden gebelerin daha fazla oranda kötü uyku kalitesine sahip oldukları saptanmıştır (her biri için; $\mathrm{p}<0.05$ ). Uyandıktan sonra kendini dinlenmemiş hisseden gebelerde kötü uyku kalitesi oranı anlamlı düzeyde daha yüksek saptanmıştır $(\mathrm{p}<0.05)$ (Tablo 2$)$.

Çalışmamızda gebelerin PUKİ puan ortalamas1 $10.04 \pm 2.98$ 'dir. Yaşam kalitesi alt boyutlarından alınan puan ortalamaları ise $26.29 \pm 33.73$ ile $55.66 \pm 21.65$ arasında değişmektedir. Gebelerin PUKİ global skoru ile yaşam kalitesi alt boyutlarının (sırasıyla; fiziksel fonksiyon, fiziksel fonksiyon rol kısitlılığı, ağrı, genel sağlı algısı, enerji/vitalite, sosyal fonksiyon, emosyonel fonksiyon rol kisitlılığı, mental sağlık alt boyutu) puan ortalamaları arasinda yapilan korelasyonda negatif yönde anlamlı bir ilişki saptanmıştır. Gebelerin PUKİ'den aldıkları puanlar 
arttıkça yaşam kalitesi alt boyutlarından alınan puanlar azalmaktadır $(\mathrm{p}<0.05)$ (Tablo 3$)$.
Kadının yaşamında gebelik ve doğum doğal bir süreç olmasına rağmen kadında fizyolojik,

\section{Tartışma}

Tablo 1. Gebelerin uyku kalitesinin iyi veya kötü olma durumunun sosyo-demografik özelliklere göre dağılımı

\begin{tabular}{|c|c|c|c|c|c|}
\hline \multirow{2}{*}{ Değişkenler } & & \multicolumn{3}{|c|}{ Uyku kalitesi (Global Skor) } & \multirow[t]{2}{*}{$X^{2} ; p$} \\
\hline & & İyi $(5<)$ & Kötü (5>) & Toplam & \\
\hline \multirow[t]{2}{*}{ Yaş } & $\leq 29$ & $109(47.4)$ & $121(52.6)$ & $230(59.6)$ & $6.219 ; 0.013$ \\
\hline & $\geq 30$ & $54(34.6)$ & $102(65.4)$ & $156(40.4)$ & \\
\hline \multirow[t]{3}{*}{ Ögrenim düzeyi } & İlköğretim & $68(36.8)$ & $117(63.2)$ & $185(47.9)$ & \\
\hline & Ortaöğretim & $52(44.1)$ & $66(55.9)$ & $118(30.6)$ & $5.565 ; 0.062$ \\
\hline & Üniversite & $43(51.8)$ & $40(48.2)$ & $83(21.5)$ & \\
\hline \multirow[t]{2}{*}{ Çalışma durumu } & Çalışmıyor & $113(40.4)$ & $167(59.6)$ & $280(72.5)$ & $1.463 ; 0.226$ \\
\hline & Çalışıyor & $50(47.2)$ & $56(42.8)$ & $106(27.5)$ & \\
\hline \multirow{2}{*}{ Yaşadı ̌̆ yer } & İl & $214(58.0)$ & $155(42)$ & $369(95.6)$ & $0.170 ; 0.680$ \\
\hline & İlçe & $9(52.9)$ & $8(47.1)$ & $17(4.4)$ & \\
\hline \multirow{2}{*}{$\begin{array}{l}\text { Hanede yaşayan kişi } \\
\text { sayısı }\end{array}$} & $1-4$ & $147(45.0)$ & $180(55.0)$ & $327(84.7)$ & $6.517 ; 0.011$ \\
\hline & $5-8$ & $16(27.1)$ & $43(72.9)$ & $59(15.3)$ & \\
\hline \multirow[t]{2}{*}{ Aylik hane geliri } & $<2000$ & $100(39.5)$ & $153(60.5)$ & $253(65.5)$ & $2.198 ; 0.138$ \\
\hline & $\geq 2000$ & $63(47.4)$ & $70(52.6)$ & $133(34.5)$ & \\
\hline \multirow[t]{3}{*}{$V K \dot{I}$} & Normal & $75(51.0)$ & $72(49.0)$ & $147(38.1)$ & \\
\hline & Fazla kilolu & $64(36.6)$ & $111(63.4)$ & $175(45.3)$ & $7.540 ; 0.023$ \\
\hline & Obez & $24(37.5)$ & $40(62.5)$ & $64(16.6)$ & \\
\hline \multirow[t]{2}{*}{ Sigara içme } & İçiyor & $30(36.6)$ & $52(63.4)$ & $82(21.2)$ & $1.359 ; 0.244$ \\
\hline & İçmiyor & $133(43.8)$ & $171(56.3)$ & $304(78.8)$ & \\
\hline Toplam * & & $163(42.2)$ & $223(57.8)$ & 386 (100.0) & \\
\hline
\end{tabular}

*Satır toplamına, **Sütun toplamına göre yüzde alınmıştır.

Tablo 2. Gebelerin Uyku Kalitesinin İyi Veya Kötü Olma Durumunun Obstetrik Özellikler ve Uyku Alışkanlıkları İle İlgili Bilgilere Göre Dağılımı

\begin{tabular}{llcccc}
\hline Değişkenler & & \multicolumn{3}{c}{ Uyku kalitesi (Global Skor) } & \multirow{2}{*}{$X^{2} ; \mathrm{p}$} \\
\cline { 3 - 5 } & $\begin{array}{c}\text { İyi }(5<) \\
\mathrm{n}(\%)^{*}\end{array}$ & $\begin{array}{c}\text { Kötü }(5>) \\
\mathrm{n}(\%)^{*}\end{array}$ & $\begin{array}{c}\text { Toplam } \\
\mathrm{n}(\%)^{* *}\end{array}$ & \\
\hline Gebelik dönemi & 1.Trimester & $45(61.6)$ & $28(38.4)$ & $73(18.9)$ & \\
& $\begin{array}{l}2 . \text { Trimester } \\
\text { 3.Trimester }\end{array}$ & $69(53.1)$ & $61(46.9)$ & $130(33.7)$ & $35.462 ;$ \\
& 1 & $61(26.8)$ & $134(73.2)$ & $183(47.4)$ & 0.000 \\
\hline Toplam gebelik saylsl & 1 & $80(43.7)$ & $103(56.3)$ & $183(47.4)$ & $13.002 ;$ \\
& $2-3$ & $22(26.2)$ & $62(73.8)$ & $84(21.8)$ & 0.002 \\
\hline
\end{tabular}


Tablo 2. Gebelerin Uyku Kalitesinin İyi Veya Kötü Olma Durumunun Obstetrik Özellikler ve Uyku Alışkanlıkları İle İlgili Bilgilere Göre Dağılımı /devam)

\begin{tabular}{|c|c|c|c|c|c|}
\hline \multirow[t]{3}{*}{ Yaşayan çocuk sayısı } & Yok & $75(48.1)$ & $81(51.9)$ & $156(40.4)$ & \\
\hline & 1 & $62(48.4)$ & $66(51.6)$ & $128(33.2)$ & 15.924; \\
\hline & $\geq 2$ & $26(25.5)$ & $76(74.5)$ & $102(26.4)$ & 0.000 \\
\hline \multirow{2}{*}{$\begin{array}{l}\text { Gebeliğin planl olma } \\
\text { durumu }\end{array}$} & Planlı & $138(45.1)$ & $168(54.9)$ & $306(79.3)$ & 4.985 \\
\hline & Plansız & $25(31.3)$ & $55(68.8)$ & $80(20.7)$ & 0.026 \\
\hline \multirow[t]{2}{*}{ Kötü obstetrik deneyim } & Var & $123(48.8)$ & $129(51.2)$ & $252(65.3)$ & 12.889; \\
\hline & Yok & $40(29.9)$ & $94(70.1)$ & $134(34.7)$ & 0.000 \\
\hline \multirow{2}{*}{$\begin{array}{l}\text { Gebelikte eşlik eden } \\
\text { hastallk }\end{array}$} & Var & $15(24.6)$ & $46(75.4)$ & $61(15.8)$ & 9.239 \\
\hline & Yok & $148(45.5)$ & $177(54.5)$ & $325(84.2)$ & 0.002 \\
\hline \multirow[t]{2}{*}{ Düzenli ilaç kullanımı } & Evet & $72(39.1)$ & $112(60.9)$ & $184(47.7)$ & 1.383; \\
\hline & Hayır & $91(45.0)$ & $111(55.0)$ & $202(52.3)$ & 0.240 \\
\hline \multirow{2}{*}{$\begin{array}{l}\text { Gebelikte uyandiktan } \\
\text { sonra kendini dinlenmiş } \\
\text { hissetme durumu }\end{array}$} & Evet & $26(72.2)$ & $10(27.8)$ & $36(9.3)$ & 14.641; \\
\hline & Hayır & $137(39.1)$ & $213(60.9)$ & $350(90.7)$ & 0.000 \\
\hline \multirow{2}{*}{$\begin{array}{l}\text { Uykuya dalmak için } \\
\text { yapulan ritüeller }\end{array}$} & Var & $60(47.2)$ & $67(57.8)$ & $127(32.9)$ & 1.952 \\
\hline & Yok & $103(39.8)$ & $156(60.2)$ & $259(67.1)$ & 0.162 \\
\hline \multicolumn{2}{|l|}{ Toplam * } & $163(42.2)$ & $223(57.8)$ & $386(100.0)$ & \\
\hline
\end{tabular}

*Satır toplamına, **Sütun toplamına göre yüzde alınmıştır.

Tablo 3. Pittsburg Uyku Kalitesi İndeksi ve SF-36 Yaşam Kalitesi Ölçeği Puan Dağılımı ve Korelasyonu

\begin{tabular}{|c|c|c|c|c|c|}
\hline & Ort. /SS & $\begin{array}{l}\text { Median } \\
\text { (25.-75. Percentile) }\end{array}$ & Min-Max & $\begin{array}{c}\text { PUKİ Global Skor } \\
\text { rho* }\end{array}$ & $\mathrm{p}$ \\
\hline PUKI & $10.04 \pm 2.98$ & $10.0(8.0-12.0)$ & $2.0-17.0$ & & \\
\hline \multicolumn{6}{|l|}{ SF-36 Alt Boyutlar } \\
\hline Fiziksel fonksiyon & $37.48 \pm 21.12$ & $35.0(20.0-55.0)$ & $0.0-95.0$ & -0.463 & $<0.001$ \\
\hline $\begin{array}{l}\text { Fiziksel fonksiyon rol } \\
\text { kisitl111 ğg }\end{array}$ & $26.29 \pm 33.73$ & $0.0(0.0-50.0)$ & $0.0-100.0$ & -0.180 & $<0.001$ \\
\hline Ağr1 & $45.17 \pm 25.67$ & $52.0(22.0-64.0)$ & $0.0-100.0$ & -0.346 & $<0.001$ \\
\hline Genel sağlık algısı & $48.31 \pm 20.10$ & $45.0(35.0-57.0)$ & $10.0-100.0$ & -0.358 & $<0.001$ \\
\hline Enerji/vitalite & $45.75 \pm 19.74$ & $45.0(30.0-60.0)$ & $0.0-100.0$ & -0.342 & $<0.001$ \\
\hline Sosyal fonksiyon & $46.04 \pm 22.24$ & $37.5(37.5-62.5)$ & $0.0-100.0$ & -0.376 & $<0.001$ \\
\hline $\begin{array}{l}\text { Emosyonel fonksiyon } \\
\text { rol kısitl11ığ1 }\end{array}$ & $28.15 \pm 35.09$ & $0.0(0.0-33.3)$ & $0.0-100.0$ & -0.295 & $<0.001$ \\
\hline Mental sağlık & $55.66 \pm 21.65$ & $56.0(36.0-76.0)$ & $12.0-96.0$ & -0.327 & $<0.001$ \\
\hline *Spearman kolerasyon tes & & & & & \\
\hline
\end{tabular}

psikolojik ve sosyal açıdan birçok değişikliği de beraberinde getirmektedir. Gebelikte uyku sorunları bu değişikliklerden biri olup, günlük yaşam kalitesini ve gebelik seyrini önemli ölçüde etkilemektedir (16,17). Bu çalışma, gebelikte uyku kalitesi ve yaşam kalitesi arasındaki ilişkiyi 
incelemek ve etki eden faktörleri belirlemek amacıyla yapılmıştır. Çalışmada PUKI toplam puan ortalamas1 $10.04 \pm 2.98$ olup, gebelerin \%57.8'i kötü uyku kalitesine (>5) sahiptir. Yapılan çalışmalar incelendiğinde gebelerde kötü uyku kalitesi oranı \%46-\%89.3 arasında değişmektedir (4,5,17-21). Çalışma bulguları diğer çalışmalar ile benzerlik göstermektedir. Bu sonuçlarla birlikte gebeliğin kötü uyku kalitesi sıklığını arttırdığı düşünülmektedir.

$\mathrm{Bu}$ çalışmada gebelerin öğrenim düzeyi, çalışma durumu, yaşadığı yer, hane içinde yaşayan sayıs1, gelir durumu, vücut kitle indeksi ve sigara içme durumunu oluşturan sosyo-demografik değişkenlerle uyku kalitesi sıklığı arasında anlamlı bir fark bulunmazken, yaş1 30 ve üzerinde olan gebelerin daha fazla kötü uyku kalitesine sahip olduğu görülmüştür. Benzer şekilde yapılan çalışmalarda yaş aralığı yüksek olan gebelerin uyku kalitesinin daha kötü olduğu bildirilmiștir $(5,22)$. Bir diğer çalıșmada 30 yaşın üstünde olan annelerin uyku süresinin azaldığı belirtilmiştir (23). Çalışma sonucumuz literatürle uyumludur. Gebenin yaşı arttıkça evde yaşayan kişi sayısının ve çocuk sayısının artacağı dolayısıyla kadının yaşla birlikte kalabalıklaşan ailesi içinde sorumlulukları ve yorgunluğunun arttığı ve uyku kalitesini olumsuz etkilendiği düşünülmektedir.

Bu çalıșmada yaşadıkları hanede 5-8 kișinin yaşadığını bildiren gebelerde kötü uyku kalitesi sıklığ 1 daha fazla belirlenmiştir. Afyonkarahisar ilinde gebe kadınlar ile yapılan bir çalışmada da ev içinde yaşayan kişi sayısı fazla olanların uyku kalitesi daha kötü bulunmuştur (24). Türklerde kadın, ailede belirleyici bir faktör, denetleyici bir güçtür (25). Yaşanan hane halkı büyüdükçe aile içinde sorunlar artmaktadır. Aile içinde birey sayısı fazla olduğunda gebe kadına düşen sorumluluklar, hane içindeki hareketlilik, iş yükü ve gürültü daha fazla olabilmektedir. Kalabalık aile ortamında yaşayan gebelerde uyku sorunlarına daha fazla rastlanmakta ve uyku kalitesi olumsuz etkilenmektedir.

Literatürde uyku kalitesi ile obesitenin yakından ilişkili olduğu, VKİ arttıkça uyku sorunlarının arttığı uyku kalitesinin azaldığ belirtilmektedir (26-28). Çalışmada kadınların \%45.3'ü gebelik öncesinde fazla kilolu olup bu kadınlarda uyku kalitesinin daha kötü olduğu saptanmıştır. Yapılan çalışmalarda bu araştırma bulgularına paralel olarak VKİ arttıkça uyku kalitesinin kötüleştiği bildirilmiştir (5,26-28). Obesite bireyin yaşamını sıkıntıya sokan beraberinde farklı sağlık sorunlarını da getiren bir durumdur. Gebelikten önce fazla kilolu olan katılımcıların gebeliğin etkisiyle birlikte kilo artış1 devam etmektedir. Gebelik başlı başına uyku kalitesini bozabileceği gibi buna artan VKİ'de eklenince kötü uyku kalitesi sıklığının arttığ1 düşünülmektedir.

Gebelik sürecinde kadın her trimesterde farklı fizyolojik ve psikolojik değişimleri deneyimlemektedir. Bu değişimler uyku kalitesi üzerinde etkili olmaktadır. Gebeler son trimesterde daha fazla uyku sorunları yaşamaktadır (29). Çalışmada üçüncü trimesterdaki gebelerin kötü uyku kalitesi oranı yüksek olup üçüncü trimesterde olan gebelerin diğer trimesterde olan gebelere göre kötü uyku kalitesi riskinin 8.60 kat daha fazla olduğu tespit edilmiştir. Yapılan çalışmalarda gebelerin son trimesterda veya gebelik haftası arttıkça uyku kalitesinin kötüleştiği bildirilmektedir (4,16,2933). $\mathrm{Bu}$ araştırma bulguları diğer çalışmalarla paralellik göstermektedir. Gebeler özellikle son trimestere geldiklerinde doğumun yaklaşmasına bağlı kaygı yaşayabilmekte aynı zamanda gece idrara çıkma ve karnın büyümesi ile birlikte yaşanan fiziksel değişimlere bağlı olarak uyku bölünmeleri artmakta, uyku süresinde azalmalar meydana gelmektedir. Bu faktörler uyku kalitesini olumsuz etkilemekte ve kötüleştirmektedir.

Bu çalışmada toplam gebelik sayısı fazla olan gebelerin kötü uyku kalitesi sıklığı daha fazladır. Bazı çalışmalarda primipar gebelerin multipar gebelere göre daha fazla uyku sorunu yaşadıkları $(34,35)$, bazı çalışmalarda da gebelik sayısının uyku kalitesine etki etmediği saptanmıştır $(5,24)$. Literatürde farklı sonuçlar olduğu görülmüştür. Çalışma bulgumuz yapılan çalışma sonuçlarından farklıdır. Gebelik sayısı fazla olan kadınların ilaveten yaşayan çocuk sayısının da fazla olduğu düşünülmektedir. Çocuklarına gebelik sürecinde bakmak zorunda olan gebelerin yorgunluğu ve artan sorumlulukları uyku kalitesini kötüleştirebilir. Nitekim bu çalışmada yaşayan çocuk sayısı fazla olan gebelerin uyku kalitesi daha kötüdür. Bu sonuca paralel Pınar ve arkadaşlarının Sivas'ta gebeler ile yaptıkları çalışmada 2 ile 5 arası çocuğu olan gebelerin uyku kalitesinin hiç çocuğu olmayanlara göre daha kötü olduğu tespit edilmiştir (22). 
Gebeliğin istenen ve planlanan bir gebelik olması kadının gebeliğe olumlu başlamasını ve sürdürmesini sağlamaktadır. Çalışmada gebeliği plansız olan kadınların kötü uyku kalitesi oranı daha fazladır. Yapılan bir çalışmada benzer sonuç bildirilmiştir (22). Başka bir çalışmada gebeliği istemeyenlerin fiziksel ve emosyonel yakınmaların daha fazla olduğu tespit edilmiştir (36). Çalışmamız bu sonuçlarla uyumlu olup, gebeliğin planlı olmaması kadının gebeliğe uyumunu zorlaştırabilir ve uyku problemlerine neden olabilir.

Çalışmada gebelerin \%15.8'ninde gebeliğe eşlik eden bir hastalığın olduğu ve bu gebelerin daha fazla kötü uyku kalitesine sahip olduğu saptanmıştır. Yapılan çalışmalarda uyku sorunu yaşayan ve uyku kalitesi kötü olan gebelerin beraberinde farklı hastaliklarının da olduğu bildirilmiștir $(5,37,38)$. Çalıșmamız literatür ile benzerdir. Bilindiği gibi yetersiz veya kalitesiz uyku fiziksel ve zihinsel sağlığımızı etkilemektedir (39). Aynı şekilde yaşanılan sağlık sorunları da uyku kalitesini etkilemektedir. Gebeliğe eşlik eden sağlık sorunları ise gebenin yaşadığ 1 fiziksel ve psikolojik değişimle beraber uyku kalitesini kötüleştirmektedir.

Uyku zihinsel dinlenme ile beraber fiziksel dinlenmeyi de sağlamaktadır. Uykudan uyandıktan sonra dinlenmemiş olarak uyanma uyku sorunlarında görülen bir bulgudur (40). Çalışmada uyandıktan sonra kendini dinlenmemiş hisseden gebeler daha yüksek kötü uyku kalitesine sahiptir. Sivas'ta gebeler ile yapılan bir çalışmada da benzer sonuç bildirilmiştir (22).

$\mathrm{Bu}$ araştırmada gebelerin SF-36 Yaşam Kalitesi Ölçeğinin alt boyutlarına göre puan ortalamaları, ağrı ve mental sağlık dışındaki tüm alt boyutlarda yaşam kalitesinin orta düzeyin altında olduğu saptanmıştır. Bulgular gebelerin genel olarak yaşam kalitelerinin düşük olduğunu göstermektedir. Ülkemizde yapılan çalışmalarda yaşam kalitesi alt boyut puan ortalamalarının genel olarak orta ve orta düzeyin üstünde olduğu görülmüştür $(9,41,42)$. Farklı ülkelerde yapılan gebelerin yaşam kalitesi puanları ise daha yüksektir (43-48). Çalışmada yaşam kalitesi puan ortalamalarının diğer çalışmalara göre daha düşük bulunmasının sebebi yaşanılan yer, sosyo ekonomik durum, kültürel özellikler ve gebeliğe ilişkin değişiklikler gibi farklı değişkenlerden kaynaklanıyor olabilir.
Çalışmada gebelerin uyku kalitesi kötüleştikçe yaşam kalitesinin de kötüleştiği saptanmıştır. Yapılan çalışmalarda uyku kalitesi düştüğünde yaşam kalitesinin de düştüğü veya uyku kalitesi arttığında yaşam kalitesinin de yükseldiği bildirilmiştir (33,49-51). Yaşam kalitesi pek çok değişkenden etkilenebilmektedir. Gebelik tek başına yaşam kalitesini düşürebildiği gibi gebelikle birlikte uyku kalitesi azaldığında bu durum yaşam kalitesi de olumsuz etkileyebilir. Çalışma bulguları literatürle uyumludur.

\section{Sonuç}

Bu çalışmada gebelerin yarısından fazlasında kötü uyku kalitesi olduğu, üçüncü trimesterde olan gebelerin kötü uyku kalitesi oranının daha fazla olduğu saptanmıştır. Bununla birlikte 30 yaş üstü, kalabalık ailede yaşayan, gebelik sayısı ve çocuk sayısı fazla olan, gebeliğe eşlik eden bir hastalığ1 olan ve plansız gebe kalan gebelerin kötü uyku kalitesi oranı daha fazladır. Bu çalışmada gebelerin yaşam kalitesi ağrı ve mental sağlık dışındaki tüm alt boyutlarda orta düzeyin altında olduğu görülmüş ve uyku kalitesi kötüleştikçe yaşam kalitesi düştügü belirlenmiştir.

$\mathrm{Bu}$ sonuçlar 1şı̆̆ında gebelerin takibi sırasında kadınların uyku kalitesi ve yaşam kalitesinin değerlendirilmesi ve risk faktörlerinin belirlenip kötü uyku kalitesi ve düşük yaşam kalitesine sahip gebe kadınlara uygun danışmanlık hizmetlerinin verilmesi önerilmektedir. Gebelikte uyku ve yaşam kalitesini yükseltmek için alternatif yöntemler geliştiren çalışmaların yapılması önerilir.

\section{Kaynaklar}

1- Algın Dİ, Akdağ G, Erdinç OO. Kaliteli uyku ve uyku bozuklukları. Osmangazi Tıp Dergisi 2016; 38(1):29-34.

2- Karadağ G, Aksoy M. Uyku regülasyonu ve beslenme. Göztepe Tip Dergisi 2009; 24(1):915.

3- Pien GW, Schwab R.J. Sleep disorders during pregnancy. Sleep 2004; 27(7):1405-1417.

4- $\quad \mathrm{Ko} \mathrm{SH}$, Chang SC, Chen $\mathrm{CH}$. A Comparative study of sleep quality between pregnant and nonpregnant Taiwanese women. Journal of Nursing Scholarship 2010;42(1):23-30.

5- Taşkıran N. Gebelik ve uyku kalitesi. Türk Jinekoloji ve Obstetrik Derneği Dergisi 2011; 8(3):181-187. 
6- Sharma S, Franco R. Sleep and its diorders in pregnancy. Wisconsin Medical Journal 2004;103(5), 48- 52.

7- Müezzinoğlu T. Yaşam kalitesi. Üroonkoloji Bülteni 2005; 1(4):25-29.

8- Eser E, Yüksel H, Sieberer UR. Çocuklar için genel amaçlı sağlıkla ilgili yaşam kalitesi ölçeği (Kid-KINDL) Türkçe sürümünün psikometrik özellikleri. Türk Psikiyatri Dergisi 2008;19 (4):409-417.

9- Özçelik G, Karaçam Z. Gebelikte sik karşılaşılan yakınmalar, fiziksel, ruhsal ve cinsel sağlık sorunları, risk faktörleri ve yaşam kalitesi ile ilişkileri. Ege Üniversitesi Hemşirelik Fakültesi Dergisi 2014; 30(3):1-18.

10- Mckee MD, Cunningham M, Zayas L. Healthrelated functional status in pregnancy: relationship to depression and social support in a multi-ethnic population. Obstetric and Gynecology 2001; 97:988-993.

11- Magee LA, Chandra K, Guyatt GH. Development of health related quality of life instrument for nausea and vomiting of pregnancy. American Journal of Obstetrics and Gynecology 2002;186(5):232-238.

12- Buysse DJ, Reynolds CF, Timothy HM, Susan RB, David JK. The Pittsburgh sleep quality index: a new instrument for psychiatric practice and research. Psychiatry Research 1988; 28:193-213.

13- Ağargün MY, Kara H, Anlar O. The validity and reliability of the Pittsburgh Sleep Quality Index. Turkish Psychiatry Journal 1996;7(2):107-115.

14- Ware JE, Sherbourne CD. The MOS 36-item Short-Form Health Survey (SF-36): I. Conceptual framework and item selection. Medical Care 1992;30, 473-83.

15- Pınar R. Sağlık araştırmalarında yeni bir kavram: Yaşam kalitesi, bir yaşam kalitesi ölçeğinin kronik hastalarda geçerlik ve güvenirliğinin sınanması. Hemşirelik Bülteni 1995;9: 85-95.

16- Çoban A, Yanıkkerem E. Gebelerde uyku kalitesi ve yorgunluk düzeyi. Ege Tip Dergisi 2010;49(2), 87-94.

17- Köybaşı EŞ, Oskay ÜY. Gebelik sürecinin uyku kalitesine etkisi. Gülhane Tıp Dergisi, 2017; 59:1.

18- Mindel JA, Cook RA, Nikolovski J. Sleep patterns and sleep disturbances across pregnancy. Sleep Medicine 2015; (16):483488.

19- Naud K, Ouellet A, Brown C, Pasquier JC, Moutquin JM. Is sleep disturbed in pregnancy? J Obstet Gynaecol Can. 2010; 32(1): 28-34.

20- Naghi I, Keypour F, Ahari SB, Tavalai SA, Khak M. Sleep disturbance in late pregnancy and type and duration of labour. J Obstet Gynaecol. 2011; 31(6): 489-91.

21- Reutrakul S, Zaidi N, Wroblewski K, Kay HH, Van Cauter E. Sleep disturbances and their relationship to glucose tolerance in pregnancy. Diabetes Care. 2011; 34(11): 2454-7.

22- Pınar ŞE, Arslan Ş, Dağlar G. Gebelerde uyku kalitesi ile algılanan stres arasındaki ilişkinin incelenmesi. Dokuz Eylül Üniversitesi Hemşirelik Yüksekokulu Elektronik Dergisi 2014; 7(3), 171-177.

23- Hedman C, Pohjasvaara T, Tolonen U, Suhonen-Malm AS, Myllyla VV. Effects of pregnancy on mothers' sleep. Sleep Medicine 2002; 3:37-42.

24- Çelik F, Köse M. Gebelikte uyku kalitesinin trimester ile ilişkisi. Kocatepe Tıp Dergisi 2017; 18:85-88.

25- Aktaş E, Teksöz E, Ocakçı AF. Ailede kadının değişen rolünün çocuk sağlığına etkisi ve aile merkezli bakımın önemi. Ege Üniversitesi Hemşirelik Fakültesi Dergisi 2012; 28 (1):7380.

26- Taheri S, Lin L, Austin D, Young T, Mignot E. Short sleep duration is associated with reduced leptin, elevated ghrelin, and increased body mass index-A population-based study. PLOS Medicine 2004; 3:e62.

27- Bixler EO, Vgontzas AN, Lin HM, Calhoun SL, Vela-Bueno A, Kales A. Excessive day time sleepiness in a general population sample: The role of sleep apnea, age, obesity, diabetes and depression. The Journal of Clinical Endocrinology\&Metabolism 2005; 90: 45104515.

28- Göktaş E, Çelik F, Özer H, Gündüzoğlu NÇ. Obez bireylerin uyku kalitesinin belirlenmesi. DEUHFED 2015; 8(3),156-161.

29- Hung HM, Tsai PS, Ko SH, Chen CH. Patterns and predictors of sleep quality in Taiwanese pregnant women. MCN Am J Matern Child Nurs. 2013; 38(2):95-101. 
30- Facco FL, Kramer J, Grobman WA. Sleep disturbances in pregnancy. Obstetrics \& Gynecology 2010; 115(1), 77-83.

31- Köybaşı EŞ, Oskay UY. Gebelik sürecinin uyku kalitesine etkisi. Gülhane Tip Dergisi 2017; 59:1-5.

32- Kamysheva E, Skouteris H, Wertheim EH, Paxton SJ, Milgrom, J. A prospective investigation of the relationships among sleep quality, physical symptoms, and depressive symptoms during pregnancy. Journal of Affective Disorders 2010; 123(1-3),317-320.

33- Süt HK, Aşçı Ö, Topak N. Sleep quality and health-related quality of life in pregnancy. J Perinat Neonat Nurs. 2016; 34(4): 302-309.

34- Signal TL, Gander PH, Sangalli MR, Travier N, Firestone RT, Tuohy F. Sleep duration and quality in healty nulliparous and multiparous women across pregnancy and postpartum, The Australian and New Zealand Journal of Obstetrics \& Gynaecology 2007; 47(1): 16-22.

35- Lee KA, Zaffke ME, Mcenany G. Parity and sleep patterns during and after pregnancy, Obstetrics \& Gynecology 2000; 95(1): 14-18.

36- Sunal N, Demiryay A. Gebe kadinların algıladıkları fiziksel ve emosyonel yakınmalar. Firat Sağl1k Hizmetleri Dergisi 2009; 4(12): 99 110.

37- Ursavaş A, Karadağ M. Sleep breathing disorders in pregnancy. Tüberküloz ve Toraks Dergisi 2009; 57(2): 237-243.

38- Lee KA, Gay CL. Sleep in late pregnancy predicts length of labor and type of delivery. American Journal of Obstetrics \& Gynecology 2004; 191(6), 2041-2046.

39- Chang JJ, Pien GW, Duntley SP, Macones GA. Sleep deprivation during pregnancy and maternal and fetal outcomes: Is there a relationship? Sleep Medicine Reviews 2010; 14: 107-114.

40- Demir B. Uyku bozuklukları. Türkiye Tip Dergisi 2002; 9(3):117-127.

41- Ünver H, Aylaz R. Gebelerde fiziksel egzersizin yaşam kalitesi üzerine etkisi. Türkiye Klinikleri Jinekoloji Obstetrik 2017; 27(2):71-8.

42- Taşdemir SB, Elçin GO, Osman G. Comparison of life quality of pregnant adolescents with taht of pregnant adults in Turkey. Upsala Journal of Medical Sciences 2010; 115(4):275-281.
43- Förger F, Otensen M, Schumacher A, Villiger PM. Impact of pregnancy on health related quality of life evaluated prospectively in pregnant women with rheumatic diseases by the SF-36 health survey. Annals of the Rheumatic Diseases 2005; 64:1494-1499.

44- Costa DD, Dritsa M, Verreault N, Balaa C, Kudzman J, Khalife S. Sleep problems and depressed mood negatively impact healthrelated quality of life during pregnancy. Arch Womens Ment Health 2010;13:249-257.

45- Fatemeh A, Azam B, Nahid M. Quality of life in pregnant women results of a study from Kashan, Iran. Pak J Med Sci. 2010; 26(3):692697.

46- Jomeen J, Martin CR. The factor structure of the SF-36 in early pregnancy. Journal of Psychosomatic Research 2005;59:131- 138.

47- Mazuchova L, Kelcikova S, Dubovicka Z. Measuring women's quality of life during pregnancy. Kontakt 2018; 20:e31-e36.

48- Nakamura Y, Takeishi Y, Atogami F, Yoshizawa T. Assessment of quality of life in pregnant Japanese women: Comparison of hospitalized, outpatient, and non-pregnant women. Nursing and Health Sciences 2012; 14:182-188.

49- Effati-Daryan F, Mirghafourvand M, Mohammad-Alizadeh-Charandabi S, ShiriSarand F, Zarei S. Sleep quality and its relationship with quality of life in Iranian pregnant women. International Journal of Practice 2017; 23:e12518.

50- Rezaei E, Moghadam ZB, Nejat S, Dehghannayeri $N$. The impact of sleep healthy behavior education on the quality of life in the pregnant women with sleep disorder: A randomized control trial in the year 2012. Iranian Journal of Nursing and Midwifery Research 2014; 19(5): 508-516.

51- Tsai SY, Lee PL, Lin JW, Lee CN. Crosssectional and longitudinal associations between sleep and health-related quality of life in pregnant women: A prospective observational study. International Journal of Nursing Studies 2016;56: 45-53. 